\title{
Kekhasan Pengajaran Bahasa Mandarin di Indonesia ${ }^{1}$
}

\author{
Hermina Sutami
}

\begin{abstract}
Mandarin teaching resurrection in Indonesia after 30 years prohibited. Since then, many schools begin to teach Mandarin as an extracurricular subject. In the last two years it becomes an intracurricular subject. Since there was no Chinese school for almost 30 years, consequently there was no publication on Mandarin student's book, no Mandarin teachers. Nowadays, suddenly Mandarin teachers, student's book was highly needed. Many schools use Singapore/Taiwan's book. This rises problems, because Singapore/Taiwan's students language circumstance is different from Indonesian students. The result is far from what we expected. This article proposed some aids based on the need of Indonesian's student. Department of Education should set up a team consisting of Indonesian experts in Mandarin language teaching and Chinese linguistic to compile syllabus, student's book. It should base on Indonesian Language Politics and the need of Indonesian's student which differ from Chinese schools 30 years ago.
\end{abstract}

KEYWORDS Pengajaran bahasa Mandarin, khas Indonesia, silabus

Dalam perkembangan dunia dewasa ini kebutuhan akan kemahiran berbahasa Mandarin-di samping bahasa Inggris - tampak semakin jelas. Pada era sebelum ini hal-hal yang dipelajari tentang RRT di fakultas sastra lebih ditujukan untuk menguasai Sinologi atau ilmu tentang Cina. Universitas Indonesia maupun universitas di Eropa dan Amerika pada beberapa puluh tahun lalu sangat menitikberatkan pengajaran dan penelitian bahasa Cina klasik. Keadaan itu kini telah berubah. Peran bahasa Mandarin dalam bisnis tak dapat diabaikan seiring dengan perkembangan perekonomian negara itu. Hal itu membuat pakar pengajaran bahasa Mandarin mau tidak mau memikirkan cara efektif untuk menghasilkan pemelajar yang juga mahir berbahasa Cina Modern atau Bahasa Mandarin, di samping menguasai Bahasa Cina klasik secara pasif.

Tulisan ini membahas masalah penguasaan bahasa Mandarin dalam hubungan dengan pengajaran bahasa itu dalam skala besar dari SMA/ SMK sampai perguruan tinggi. Kami berpendapat sistem pengajaran di satu jenjang tidak terlepas dari sistem di jenjang lain sehingga tidak terjadi ketumpangtindihan tujuan yang mengakibatkan pengajaran tanpa tujuan

\footnotetext{
Makalah ini telah diseminarkan pada Seminar Bahasa Tionghoa: Problema Penguasaannya dan Perannya dalam Bisnis Internasional yang diadakan Program Studi Cina FIB UI, 22 Juni 2006, dan telah mengalami perubahan untuk kepentingan Jurnal Wacana FIB UI.
} 
jelas serta terkesan asal-asalan. Namun, bahasa itu tetap diajarkan karena sedang ngetrend. Ketidakmengertian pengajar terhadap metode dan teknik mengajar, ketiadaan silabus, dan ketidakmampuan memilih buku ajar yang tepat merupakan penyebabnya. Dalam situasi seperti ini para lulusan belum dapat menunjukkan kinerjanya di dunia bisnis internasional.

Hal lain yang akan dikupas berkaitan dengan pengajaran bahasa Mandarin yang efektif pada jalur pendidikan formal. Efektif berarti tepat guna dan tepat sasaran. Fokus perhatian adalah bagaimana membuat pemelajar mahir berbahasa Mandarin, kemahiran yang berguna dan bermanfaat pada bidang yang dipilih atau diminatinya. Berhubungan dengan itu, akan diketengahkan kekurangan dari pengajaran yang sedang berlangsung serta upaya pembenahan dan pengaturan dengan memperhatikan politik bahasa nasional pemerintah Indonesia.

\section{KeduduKan Bahasa Mandarin di IndOnesia}

Bahasa Indonesia sebagai bahasa persatuan sudah kita ketahui. Pengikrarannya dilakukan dalam Sumpah Pemuda tanggal 28 Oktober 1928, serta dinyatakan dalam Undang-Undang Dasar 1945, Bab XV, Pasal 36 sebagai bahasa negara. Sebagai bahasa persatuan, Bahasa Indonesia juga disebut bahasa nasional atau bahasa kebangsaan. Selain itu, terdapat dua golongan bahasa lainnya, yakni bahasa daerah dan bahasa asing. Yang dimaksud dengan bahasa daerah adalah:

bahasa yang dipakai sebagai bahasa perhubungan intradaerah atau intramasyarakat di samping Bahasa Indonesia dan yang dipakai sebagai sarana pendukung sastra serta budaya daerah atau masyarakat etnik di wilayah Republik Indonesia. Bahasa-bahasa daerah merupakan bagian dari kebudayaan Indonesia yang hidup. (Alwi dan Dendy 2003: 4)

Di mana kedudukan bahasa Mandarin di Indonesia, sebagai bahasa daerah atau bahasa asing? Menurut Rumusan Seminar Politik Bahasa $1999^{2}$ (Alwi dan Dendy 2003: 4), yang dimaksud dengan bahasa asing di Indonesia adalah:

semua bahasa, kecuali Bahasa Indonesia, bahasa-bahasa daerah, dan bahasa serumpun Melayu. Bahasa asing yang berfungsi sebagai bahasa ibu warga negara Indonesia kelompok etnis tertentu tetap berkedudukan sebagai bahasa asing.

Dengan demikian, bahasa Mandarin tergolong bahasa asing walaupun ada kelompok warga negara Indonesia yang berbahasa ibu bahasa Mandarin.

Dalam hubungan dengan pembinaan dan pengembangan bahasa asing, pengajaran bahasa Mandarin ditujukan kepada upaya penguasaan dan pemakaian bahasa itu, terutama untuk pemanfaatan ilmu dan teknologi dalam menyikapi persaingan bebas pada era globalisasi, agar lebih banyak orang Indonesia mampu memanfaatkan informasi dalam bahasa Mandarin. Dengan demikian, bahasa ini dianggap sebagai alat untuk membantu mempercepat proses pembangunan negara dan bangsa, dan sebagai alat komunikasi dengan

\footnotetext{
2 Seminar Politik Bahasa diadakan di Cisarua, Bogor, 8-12 November 1999.
} 
bangsa lain (Kartono 1980; Retmono 1980), dalam hal ini bangsa Cina di RRT, Taiwan, Singapura, Malaysia, dan di tempat lainnya. Adapun pembinaan yang dimaksud di atas adalah:

upaya untuk meningkatkan mutu pemakaian bahasa. Usaha-usaha pembinaan itu mencakup upaya peningkatan sikap, pengetahuan, dan keterampilan berbahasa yang dilakukan, antara lain, melalui pengajaran dan pemasyarakatan. (Alwi dan Dendy 2003: 9)

Kegiatan yang berhubungan dengan peningkatan mutu pengajaran Bahasa Mandarin:

a) pengembangan kurikulum;

b) pengembangan bahan ajar yang sesuai dengan kebutuhan siswa dalam era global dan dengan perkembangan metodologi pengajaran bahasa;

c) pengembangan tenaga pengajar Bahasa Mandarin yang profesional;

d) pengembangan sarana pengajaran Bahasa Mandarin yang memadai;

e) pemanfaatan teknologi informasi dalam Bahasa Mandarin.

Sesuai dengan sifat dan jenis pendidikan, Bahasa Mandarin dapat diajarkan sebagai mata pelajaran wajib atau pilihan. Sebagai mata pelajaran pilihan bahasa itu diberikan pada jenjang pendidikan menengah dan pendidikan tinggi. Mengenai pengembangan bahasa, yang dimaksud dengan pengembangan ialah

upaya meningkatkan mutu bahasa agar dapat dipakai untuk berbagai keperluan dalam kehidupan masyarakat modern. Upaya pengembangan itu, antara lain, meliputi penelitian, pembakuan, dan pemeliharaan. (Alwi dan Dendy 2003: 13)

Dalam hubungan bahasa Mandarin sebagai bahasa asing, kegiatan yang relevan dilakukan adalah penelitian. Penelitian terhadap bahasa Mandarin perlu dilakukan untuk mencegah dampak negatif terhadap pertumbuhan dan perkembangan bahasa Indonesia. Selain itu, penelitian ini dapat dimanfaatkan untuk memperkaya bahasa Indonesia, misalnya penelitian di bidang kata serapan. Penelitian juga dapat dilakukan di bidang pengajaran bahasa Mandarin, tujuannya meningkatkan mutu pengajaran. Pembakuan dan pemeliharaan merupakan upaya pengembangan yang tidak dilakukan terhadap bahasa Mandarin sebagai bahasa asing di Indonesia.

Secara singkat, hasil Seminar Politik Bahasa (1999), dalam hubungan dengan Bahasa Mandarin sebagai bahasa asing, dapat disarikan ke dalam empat butir.

a) Bahasa Mandarin merupakan bahasa asing.

b) Pembinaan terhadap bahasa Mandarin perlu dilakukan, antara lain melalui peningkatan mutu pengajarannya.

c) Bahasa Mandarin dapat diajarkan sebagai mata pelajaran wajib atau pilihan: wajib pada program studi yang khusus mengajarkan bahasa itu, misalnya program studi Cina, diploma Cina; pilihan pada tingkat sekolah menengah seperti SMP, SMA dan sejenisnya, tingkat universitas 
atau sejenisnya.

d) Pengembangan bahasa Mandarin dilakukan melalui penelitian guna memperkaya bahasa Indonesia, meningkatkan mutu pengajaran bahasa Mandarin di Indonesia atau mencegah dampak negatif bahasa itu terhadap pertumbuhan dan perkembangan bahasa Indonesia.

\section{Latar Belakang Pengajaran Bahasa Mandarin di Indonesia}

Secara kronologis, pengajaran bahasa Mandarin di Indonesia dapat dibedakan atas dua kelompok besar. Pembagian itu didasarkan pada kebijakan beberapa pemerintah selama kurun waktu itu.

\section{Sebelum KemerdekaAn RI}

Pengajaran bahasa Mandarin sebelum Indonesia merdeka berlangsung pada masa penjajahan Belanda dan Jepang. Pada kedua zaman penjajahan itu pengajaran bahasa Mandarin dianggap sewajarnya diberikan kepada anakanak Cina. Akan tetapi, tidak semua anak Cina mengenyam pendidikan di sekolah Cina.

Bahasa Mandarin dan Hokkian diajarkan pada zaman Belanda. Namun, sejak kehadiran VOC di Batavia di bawah pimpinan Jan Pieterszoon Coen, sejak tahun 1619 sampai puluhan tahun berikutnya, tidak ada satu pun sekolah berbahasa Cina didirikan oleh pemerintah Belanda ${ }^{3}$. Akibatnya keluarga Cina kaya mendatangkan pengajar privat dari Cina untuk memberi pelajaran dari kitab klasik kepada anak-anak mereka.

Tahun 1753 masyarakat Cina Batavia mendirikan sekolah untuk tujuan amal, jumlah muridnya sekitar 30-40 anak Cina peranakan. Akan tetapi, sekolah itu bangkrut karena salah urus administrasi. Tahun 1775 dibuka sekolah Gie Oh yang menggunakan bahasa Hokkian sebagai bahasa pengantar. Pada tahun 1783 Ong Tae-Hae (Wang Dahai) yang berasal dari provinsi Fujian datang ke pulau Jawa membuka sekolah swasta di Batavia, Semarang, dan Pekalongan selama satu dasawarsa. Ketika ia kembali ke negeri asalnya, tidak ada pengajar pengganti, dengan sendirinya sekolah itu ditutup (Govaars 2005: 38).

Tahun 1901 perkumpulan orang Cina di Nusantara yang bernama Tionghoa Hwee Kuan (THHK) mendirikan sekolah dengan kurikulum baru yang didasarkan pada ajaran moral Konfusius. Mata pelajaran yang diajarkan berasal dari Barat, seperti berhitung, sejarah, ilmu bumi, ilmu alam, membaca, menulis. Semua pelajaran diberikan dalam bahasa Mandarin. Pengajarpengajarnya didatangkan dari negara Cina. Kehadiran sekolah THHK di Batavia memberi inspirasi pada masyarakat Cina di kota lain untuk membuka sekolah sejenis ${ }^{4}$. D.E. Willmott dalam The Chinese of Semarang melaporkan pada

3 Kedatangan Cina Muslim abad 15 yang mendirikan sekolah Islam menyebabkan sejumlah anak Cina mengenyam pendidikan sekolah dasar di langgar dan sekolah menengah di pesantren (Govaars 2005:37).

Di samping dididik di sekolah THHK, banyak anak Cina Peranakan mengenyam pendidikan di sekolah yang didirikan pemerintah Belanda seperti HCS (Holland Chineese 
1920 terdapat 442 sekolah THHK dengan jumlah jumlah murid 20.000, pada 1926 jumlah muridnya bertambah menjadi 32.000 (Govaars 2005: 62).

Pada masa penjajahan Jepang (1942-1945) sekolah berbahasa Mandarin tetap diperbolehkan, sedangkan sekolah berbahasa Belanda ditutup. Semua anak Cina peranakan yang sebelumnya bersekolah di HCS beralih ke sekolah berbahasa Mandarin ${ }^{5}$.

\section{SESUDAH KeMERDEKAAN RI}

Setelah Indonesia merdeka, sekolah berbahasa Belanda ditutup tahun 1949. Anak-anak Cina yang sebelumnya mengenyam pendidikan di sekolah Belanda beralih ke sekolah berbahasa pengantar Indonesia atau berbahasa pengantar bahasa Mandarin. Akibatnya, terjadi peningkatan jumlah sekolah Cina. Dari 1952-1953 di Kementerian Pendidikan terdaftar 1.371 sekolah Cina dengan jumlah murid 254.730. Pengajarnya didatangkan dari Beijing atau Taiwan, ditambah pengajar lokal lulusan sekolah Cina di Indonesia. Pada saat itu, terdapat dua aliran sekolah Cina, ada yang pro-Taiwan; ada yang pro-Peking. Sampai tahun 1957 pemerintah Indonesia membolehkan warga negara Indonesia dididik di sekolah Cina.

Sehubungan dengan situasi politis, 6 November 1957 Menteri Pertahanan Djuanda mengeluarkan peraturan bahwa warga negara Indonesia dilarang masuk sekolah Cina. Pemerintah mengurangi jumlah sekolah Cina, anakanak Cina Peranakan tidak boleh "ditotokkan" kembali seperti pada zaman Jepang. Perubahan ini terlihat dari 2000 sekolah berbahasa Mandarin dengan 425.000 murid pada November 1957 berkurang menjadi 850 sekolah dengan murid 150.000 pada Juli 1958 (Suryadinata 1984:159-160). Walaupun terjadi pengurangan, bahasa Mandarin tetap diajarkan di sekolah-sekolah Cina tersebut.

Seiring dengan pengurangan itu, 1.100 sekolah berbahasa Mandarin diubah menjadi sekolah nasional Indonesia. Pengelolaan sekolah baru ini dilakukan oleh Baperki, disebut sekolah Baperki. Kurikulumnya sama dengan sekolah Indonesia, hanya saja bahasa Mandarin boleh diajarkan sebagai salah satu mata pelajarannya.

Keadaan demikian berlangsung sampai terjadinya G-30S/PKI 1965. Setelah peristiwa itu, semua sekolah Cina ditutup, sekolah Baperki diambil alih oleh pemerintah. Anak Cina WNA tidak diberi pendidikan selama dua tahun. Tahun 1968 melalui Peraturan Presiden No.B 12/Pres./1/1968 golongan Cina swasta diizinkan mendirikan sekolah yang bernama Sekolah Nasional Proyek Chusus (SNPC). Sekolah ini berbahasa pengantar bahasa Indonesia. Bahasa Mandarin diberikan hanya beberapa jam seminggu. Keunikan sekolah ini,

School) yang berbahasa pengantar bahasa Belanda dengan mengikuti kurikulum Eropa. Di sekolah ini bahasa dan kebudayaan Cina tidak diajarkan. Anak-anak Cina miskin hanya mampu bersekolah di sekolah Melayu (Suryadinata 1984:154).

5 Mulai 1 Agustus 1942 pemerintah Jepang hanya membolehkan sekolah berbahasa Indonesia dan Cina terus beroperasi. Penguasa Jepang memperlakukan Cina totok dan peranakan sebagai "sama-sama tak berharga dan memaksa agar organisasi mereka menjadi satu". Cina peranakan dianjurkan belajar bahasa Mandarin (Suryadinata 1984:156). 
nilai jelek siswa dalam mata pelajaran bahasa Mandarin tidak memengaruhi kenaikan kelas.

Sampai 1971 ada delapan sekolah SNPC, tetapi jumlahnya semakin membesar karena orang Cina asing boleh mendapat pendidikan di sekolah itu. Namun, ada laporan yang mengatakan bahwa SNPC diSumatra menggunakan bahasa Mandarin sebagai bahasa pengantar. Hal ini melanggar peraturan pemerintah. Akibatnya, tahun 1975 Menteri Pendidikan dan Kebudayaan Mashuri mengeluarkan peraturan menghapus semua SNPC, dialihkan menjadi sekolah nasional swasta (Suryadinata 1984:167). Dengan demikian, mulai tahun 1975 secara resmi tidak ada lagi sekolah yang menjadikan bahasa Mandarin sebagai salah satu mata pelajarannya, dan sejak 1965 juga tidak ada lagi sekolah yang berbahasa pengantar bahasa Mandarin.

Namun di tingkat perguruan tinggi, satu-satunya universitas yang dibolehkan tetap membuka Program Studi Cina adalah Universitas Indonesia. Pada 1986 Universitas Dharma Persada juga membuka Program Studi Cina. Pengajaran bahasa Mandarin menjadi semakin "terbuka" setelah reformasi di tahun 1998.

\section{Situasi Pengajaran Bahasa Mandarin Dewasa ini}

Pada tahun 2000 Presiden Abdurrachman Wahid menerbitkan Keppres no.6 tahun 2000 tentang pembolehan orang Cina menjalankan segala bentuk ekspresi kebudayaan Cina, termasuk mempelajari bahasa Cina beserta aksaranya. Dengan adanya Keppres ini serta-merta minat mempelajari bahasa Mandarin tersalurkan secara terbuka ${ }^{6}$ dalam bentuk pengajaran nonformal maupun formal. Dewasa ini bahasa Mandarin diajarkan dari tingkat sekolah dasar sampai sekolah menengah umum, bahkan ada playgroup menawarkan pengajaran bahasa Mandarin kepada kanak-kanak usia prasekolah. Sejumlah sekolah - terutama yang siswanya mayoritas keturunan Cina-mengajarkan bahasa itu sebagai mata pelajaran wajib atau ekstrakurikuler. Ada kesan bahwa mata pelajaran itu diadakan hanya karena bahasa Mandarin sedang populer di masyarakat.

Dari pengamatan terhadap sekolah-sekolah tersebut diperoleh pandangan umum bahwa pengajaran bahasa Mandarin lebih banyak mengandung kekurangan daripada kelebihan. Kelebihannya adalah membangkitkan minat orang yang mampu berbahasa Mandarin menjadi pengajar. Kekurangannya ditinjau dari beberapa hal.

(1) Kebakuan bahasa

Bahasa yang diajarkan belum semuanya memenuhi kriteria bahasa Mandarin Baku (BMB) seperti yang tercermin pada lafal, intonasi, ejaan dan gramatika. Hal itu berkaitan dengan penguasaan bahasa Mandarin para pengajar yang memperoleh kemahiran berbahasa Mandarin di sekolah Cina Indonesia. Dari sudut fonetik - segmental dan suprasegmental - bahasa Mandarin Indonesia (BMI) dipengaruhi oleh

6 Semasa pemerintahan Presiden Suharto pengajaran Bahasa Mandarin dilakukan secara diam-diam dalam bentuk les privat. 
bahasa daerah di RRT seperti bahasa Hokkian, Hakka, Tiociu dan juga bahasa daerah di Indonesia, antara lain bahasa Jawa dan Sunda. Pada BMI tidak terdapat bunyi retrofleks yang sangat kental seperti dalam BMB, ada kalimat berbahasa Mandarin tetapi berintonasi bahasa Jawa, Sunda atau bahasa Indonesia, susunan $\mathrm{SPO}_{\text {taklangsung }} \mathrm{O}_{\text {langsung }}$ diterapkan kepada semua kalimat berbahasa Mandarin. Dalam hal ejaan, banyak pengajar tidak menguasai ejaan Hanyu Pinyin yang menggunakan huruf Latin. Ejaan ini merupakan sarana mempelajari bahasa Mandarin pada tahap awal. Ketidakmampuan ini disebabkan para pengajar itu tidak mempelajari ejaan Pinyin - yang menggunakan huruf Latin - saat mereka bersekolah dulu. Sebaliknya, anak-anak Indonesia justru akrab dengan huruf Latin, tidak kenal karakter Han. Memaksa siswa langsung dapat membaca dan menulis karakter Han merupakan hal yang hampir-hampir mustahil.

(2) Buku ajar

Buku ajar yang beredar di pasaran belum memenuhi kebutuhan anak Indonesia. Pihak sekolah menyerahkan pilihan dan penentuan buku ajar kepada pengajar yang bersangkutan. Pada umumnya, buku ajar yang digunakan merupakan terbitan RRT, Taiwan dan Singapura. Buku-buku itu ditujukan bagi siswa yang sedikit banyak sudah berbahasa Mandarin (Singapura), atau bahasa itu memang bahasa ibunya (RRT, Taiwan). Oleh karena itu, buku-buku tersebut sudah menggunakan karakter Han sekalipun ditujukan kepada murid sekolah dasar. Secara visual, mereka lebih mudah mencerna dan menghafal bentuk karakter Han yang akrab dalam kehidupannya. Sebaliknya, anak Indonesia "buta" terhadap karakter Han. Pemilihan buku demikian jelas tidak tepat. Buku mana yang dipilih bergantung pada kualitas pengajar. Tidak jarang buku untuk pemelajar dewasa diberikan kepada siswa SMP atau SMA.

(3) Pengajar

Ada hal menarik untuk diungkapkan mengenai orang yang menyebut dirinya "pengajar". Para "pengajar" ini dapat diklasifikasikan sebagai berikut.

(a) Mereka yang semasa diperbolehkannya berdiri sekolah Cina memang sudah berprofesi sebagai pengajar, seperti pengajar sejarah, pengajar berhitung, pengajar ilmu bumi, pengajar bahasa Mandarin. Kelompok ini rata-rata berusia di atas 50 tahun. Kemampuan berbahasa Indonesia mereka pada umumnya tidak begitu baik, hanya menguasai ragam percakapan sehari-hari.

(b) Mereka yang pernah mengenyam pendidikan sekolah Cina sampai tingkat sekolah menengah pertama (chuzhong) atau menengah atas (gaozhong). Kemahiran berbahasa Mandarin dan bahasa Cina klasik mereka yang di tingkat SMU lebih tinggi daripada yang di tingkat SMP. Kemampuan berbahasa Indonesianya ada yang seperti kelompok (1), tetapi ada yang baik.

(c) Mereka yang pernah mengenyam pendidikan sekolah Cina di tingkat sekolah dasar (xiaoxue). Kemahiran bahasa Mandarin mereka 
masih pada taraf dasar, sedangkan kemahiran bahasa Indonesianya beragam. Jika mereka melanjutkan ke sekolah berpengantar bahasa Indonesia, setidaknya sampai tingkat SMU, bahasa Indonesianya pasti lebih baik daripada yang hanya sampai tingkat SMP saja.

(d) Mereka yang setelah Peristiwa Mei 1998 pergi belajar Bahasa Mandarin ke RRT. Pengajar tamatan SMU, bahasa Indonesianya lebih baik daripada tiga golongan di atas. Lafal bahasa Mandarinnya juga lebih baik, karena sebagian besar belajar bahasa Mandarin di RRT, sehingga lafalnya belum terpengaruh lafal bahasa Mandarin Indonesia. Di sana mereka mengikuti kursus bahasa Mandarin untuk orang asing selama 1-2 tahun. Ada yang meneruskan belajar bisnis dan bidang lainnya. Namun, di RRT tidak ada kursus untuk menjadi pengajar. Mereka ini setelah kembali ke Indonesia mencoba menjadi pengajar.

(e) Lulusan Program Studi S1 Cina dan Program Diploma 3 FIB UI dan Universitas Darma Persada atau universitas lainnya seperti Universitas Petra, Universitas Maranatha, dan sebagainya. Mereka menyelesaikan studi Cina di Indonesia. Bahasa Indonesianya baik, dan Bahasa Mandarinnya baku.

Lima jenis kelompok inilah yang menjadi pengajar bahasa Mandarin di sekolah-sekolah di Jakarta. Dari sudut keprofesian kelompok pertama tidak asing lagi mengajar di depan kelas, tetapi hanya sedikit dari mereka yang memang pengajar bahasa. Kelompok kedua terdiri dari mereka yang memang tidak berprofesi sebagai pengajar. Mereka diangkat sebagai "pengajar" karena dianggap sebagai penutur asli. Seorang penutur asli oleh awam diasumsikan juga pengajar bahasa, sehingga secara otomatis dianggap pantas menjadi "pengajar". Dengan demikian, jadilah mereka pengajar bahasa Mandarin tanpa memiliki pengetahuan metode mengajar bahasa atau pengetahuan budaya Cina. Bila intuisinya sebagai pengajar cukup kuat, ia akan memilih buku ajar yang tepat dan menggunakan teknik mengajar yang tepat dan baik. Kelompok ketiga tidak berbeda jauh dengan kelompok kedua. Dari segi kemahiran bahasa Mandarin pada umumnya mereka meningkatkan kemahiran bahasanya di lingkungan keluarga, pergaulan atau meningkatkan diri melalui les privat dan belajar mandiri. Kelompok keempat dan kelima paling sempurna di bidang fonetik dan tata bahasanya. Mereka yang belum memperdalam kemahiran bahasa Mandarinnya di RRT atau negara lainnya masih perlu mendapat pelatihan kemahiran bahasa Mandarin.

Kelima golongan di atas pada dasarnya bukan tamatan sekolah pengajar. Dengan latar belakang bukan sebagai pengajar bahasa dapat diperkirakan bagaimana kualitas pengajaran mereka dan hasil yang diberikan. Siswa tidak menguasai ejaan Hanyu Pinyin, lafal tidak baku, apalagi karakter Han. Mereka hanya menguasai percakapan yang sangat sederhana seperti salam, memperkenalkan diri dalam bentuk kalimat sederhana. Yang memperparah keadaan walaupun nilai ulangan bahasa Mandarin jelek, hal itu tidak 
memengaruhi kenaikan kelas. Ini membuat siswa malas, acuh tak acuh belajar. Terlebih lagi tidak ada teknik menghapal karakter Han secara logis. Di dalam benak mereka tertanam pendapat bahwa bahasa Mandarin sangat susah, apalagi karakternya.

Dengan kualitas pengajar seperti saat ini, tidak mengherankan bila tujuan pengajaran tidak tercapai. Penyebabnya karena pengajar tidak tahu metode dan teknik mengajar, bahan ajar yang dipilih tidak sesuai dengan kebutuhan anak Indonesia. Terlebih lagi, mereka tidak dapat menyampaikan pelajaran dengan baik karena bahasa Indonesianya pun tidak baik.

Di tingkat perguruan tinggi keadaan pengajaran bahasa Mandarin dalam hal kurikulum, pengajar, dan buku ajar lebih terarah. Ditjen Dikti sudah membuat kurikulum untuk fakultas sastra yang memuat mata kuliah yang wajib diajarkan (acuan). Dosen perguruan tinggi paling kurang harus bergelar S1. Penutur asli boleh dimanfaat kemahiran bahasanya dalam pengajaran bahasa. Akan tetapi, pengajaran ilmu memberi warna kepada strata S1.

\section{Tujuan Pengajaran Bahasa Mandarin Dewasa ini}

Dengan mengacu kepada Rumusan Seminar Politik Bahasa 1999 pengajaran bahasa Mandarin merupakan pengajaran bahasa asing yang setara dengan pengajaran Bahasa Inggris. Penguasaan dan pemakaian keduanya adalah untuk pemanfaatan ilmu dan teknologi dalam era globalisasi ini, antara lain melengkapi diri dengan kemahiran berbahasa Mandarin dalam menghadapi persaingan di bidang bisnis.

Adapun tujuan pengajaran bahasa Mandarin secara umum adalah menghasilkan penutur yang mampu berkomunikasi secara lisan maupun tulis dengan penutur asli bahasa itu, membaca buku dan bahan cetak lainnya yang menggunakan aksara Han. Tujuan khusus pada tahap lanjut adalah mempelajari ilmu pengetahuan dari negara tersebut seperti sejarah, politik, seni, obat-obatan Cina, pengobatan tradisional akupungtur, dan sebagainya. Akan tetapi, tujuan dalam hubungan antarbangsa adalah memahami kebudayaan, adat istiadat dan kebiasaan orang Cina melalui bahasanya. Tujuan ini perlu digarisbawahi, mengingat jumlah penduduk Indonesia keturunan Cina cukup banyak dan peran mereka di bidang ekonomi sangat menonjol. Dengan pemahaman budaya melalui bahasa diharapkan seluruh rakyat Indonesia, baik pribumi maupun nonpribumi keturunan Cina, hidup saling hormat menghormati, penuh rasa persaudaraan tanpa rasa curiga sebagai akibat tidak memahami latar belakang budaya masing-masing. Dengan demikian, apa yang disebut "masalah Cina" dan Peristiwa Mei 1998 atau yang serupa tidak terjadi lagi.

Sesuai dengan Rumusan Seminar Politik Bahasa 1999, bahasa Mandarin baru diajarkan sebagai mata pelajaran penuh di jenjang pendidikan sekolah menengah. Kami berpendapat sebaiknya bahasa ini mulai diajarkan di sekolah menengah atas seperti SMA dan $\mathrm{SMK}^{7}$. Kemahiran pada jenjang ini berada

\footnotetext{
Kami berpendapat pelajaran bahasa Mandarin mulai diberikan diSMA/SMK, sejajar dengan pengajaran bahasa asing kedua seperti bahasa Jerman, Prancis atau Arab. Murid SD dan
} 
pada tingkat dasar yang merupakan tahap awal untuk kemahiran tingkat lanjut di perguruan tinggi. Dengan demikian terdapat kesinambungan antara pengajaran di jenjang sekolah menengah dan perguruan tinggi. Di jenjang perguruan tinggi Bahasa Mandarin diajarkan di S1 dan D3. Tujuan pengajaran di S1 dan D3 berbeda.

Kesinambungan di atas terlihat dari tujuan dan sasaran yang hendak dicapai. Pengajaran di SMA/SMK bertujuan menghasilkan pelajar yang mempunyai kemampuan dasar dalam komunikasi lisan dan tulis. Mereka diharapkan dapat berkomunikasi dengan penutur Bahasa Mandarin dalam kehidupan sehari-hari dengan topik percakapan sederhana.

Program S1 bertujuan menghasilkan tenaga peneliti. Mahir berbahasa Mandarin saja bukan tujuan pengajaran bahasa Mandarin di S1. Lulusan S1 akan dibekali ilmu seperti sastra, sejarah, budaya, linguistik, dan politik. Setelah lulus, mereka dapat memanfaatkan ilmunya di pusat-pusat penelitian atau departemen. Pembekalan ilmu tidak diberikan di D3. Jika sebuah institusi penyelenggara S1 hanya menekankan kelancaran bicara bahasa Mandarin saja, tempat menimba kemahiran itu bukan di S1 Cina, melainkan D3 Cina atau kursus bahasa Mandarin. Tujuan pengajaran D3 adalah menghasilkan tenaga siap pakai di bidang tertentu seperti pariwisata sebagai pemandu wisata, bank, perusahaan sebagai sekretaris, penerbit sebagai penyunting atau jurnalistik.

Mengingat kebutuhan tenaga pengajar yang cukup besar, fakultas ilmu pendidikan perlu membuka program studi bahasa Mandarin untuk menghasilkan pengajar bahasa Mandarin. Tenaga penerjemah dan juru bahasa juga diperlukan, tetapi bidang ini memerlukan pendidikan khusus dengan kualifikasi sarjana S1.

Berpedoman pada Rumusan Politik Bahasa, berikut ini disajikan perbedaan tingkat kemahiran serta perbedaan sasaran pengajaran bahasa Mandarin antara SMA/SMK dengan S1 dan D3:

Bagan 1. Perbedaan tingkatan kemahiran bahasa Mandarin

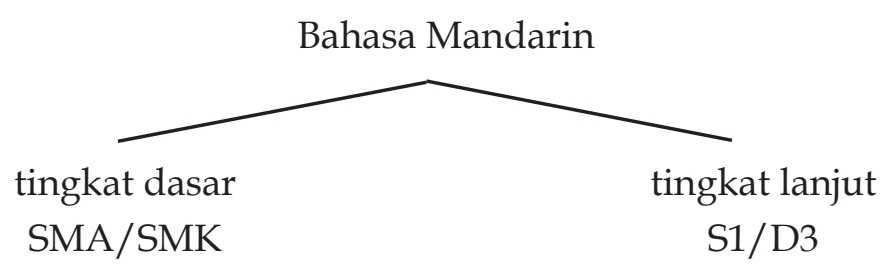

SMP sebaiknya tidak diajarkan dulu. Dalam usia itu sebaiknya siswa SD dan SMP lebih dahulu ditempa menguasai bahasa nasional sampai baik. Setelah mempunyai dasar yang kuat dan baik, baru diajarkan bahasa asing. Dengan demikian perkembangan bahasa Indonesia mereka di tingkat selanjutnya tidak "terganggu". Alasan lain, pemikiran bahwa bahasa Indonesia sebagai lambang kebanggaan kebangsaan, identitas nasional, persatuan bangsa dan alat perhubungan antardaerah dan antarbudaya (Halim 1980:23) sudah sepatutnya ditanamkan sejak usia dini. Tujuannya, agar perhargaan terhadap Bahasa Indonesia tidak luntur oleh karena bahasa asing. 
SMA dan SMK berada pada tingkat kemahiran dasar. Perbedaan bidanglah yang memberi ciri khusus kepada sekolah kejuruan. Di SMA topik pelajaran mengenai hal-hal umum; sedangkan di SMK sudah berada di bidang kejuruan sekolah yang bersangkutan. Geografi, tata cara melayani tamu, mendeskripsikan keunikan budaya atau alam suatu daerah, perhotelan, dan sebagainya adalah ciri pelajaran di sekolah pariwisata. Begitu halnya dengan sekolah kejuruan lain. Pada sekolah menengah ekonomi diajarkan membuat surat resmi, surat dagang, pembukuan ringan, dan sebagainya.

S1 dan D3 berada tingkat kemahiran lanjut yang lebih "dalam" dari pada tingkat dasar. Perbedaannya, lulusan S1 dan D3 mendapat bekal budaya Cina yang lebih mendalam. Selain itu, S1 mendapat bekal ilmu Sinologi, D3 mendapat bekal ilmu praktis yang dapat langsung digunakan untuk bekerja di kantor, bank, dan perusahaan. Bahasa Mandarin bisnis baru dapat diajarkan setelah seseorang menguasai Bahasa Mandarin umum dengan penguasaan sekitar 2.000 karakter Han. Tabel (1) di bawah ini menunjukkan sasaran yang hendak dicapai dari dua tingkatan itu.

Tabel 1. Sasaran pengajaran tingkat dasar dan lanjut

\begin{tabular}{|c|c|}
\hline Tingkat Dasar (SMA/SMK) & Tingkat Lanjut (S1/D3) \\
\hline $\begin{array}{l}\text { 1. Mengerti percakapan seder- } \\
\text { hana }\end{array}$ & $\begin{array}{l}\text { 1. Mengerti percakapan dengan } \\
\text { topik kompleks }\end{array}$ \\
\hline $\begin{array}{l}\text { 1. Mampu berbicara dengan topik } \\
\text { sederhana, dapat menyanyi } \\
\text { lagu pop }\end{array}$ & $\begin{array}{l}\text { 1. Mampu berbicara dengan } \\
\text { topik kompleks atau bidang } \\
\text { tertentu }\end{array}$ \\
\hline $\begin{array}{l}\text { 1. Mampu membaca dan menulis } \\
\text { dalam ejaan Hanyu Pinyin }\end{array}$ & $\begin{array}{l}\text { 1. Mampu membaca dan menulis } \\
\text { dalam karakter Han }\end{array}$ \\
\hline 1. Menguasai 250 kata & 1. Menguasai 3.000 kata \\
\hline \multirow[t]{2}{*}{$\begin{array}{l}\text { 1. Mampu menulis } 75-100 \text { kara- } \\
\text { kter }\end{array}$} & $\begin{array}{l}\text { 1. Mampu menulis } 2.500 \text { karakter } \\
\text { Han }\end{array}$ \\
\hline & $\begin{array}{l}\text { 1. Mampu membuat karangan } \\
\text { dengan karakter Han }\end{array}$ \\
\hline
\end{tabular}

\section{Upaya Pembenahan}

Beberapa sumbangan pikiran akan diajukan dalam membenahi sistem pengajaran yang sedang berlangsung. Pembenahan terasa mendesak dilakukan pada tingkat sekolah menengah. Sejak 2004 Departemen Pendidikan Nasional dengan direktorat jenderal terkait, Ditjen Pendidikan Menengah dan Dasar (Dikmendas), mengeluarkan kurikulum pengajaran bahasa Mandarin tingkat SMA/SMK beserta buku ajarnya. Akan tetapi, bahan ajar itu tidak mencerminkan kurikulumnya. 
Yang perlu dibenahi adalah kurikulum, silabus, pengajar, dan buku ajar. Untuk menghasilkan kurikulum, silabus, dan buku ajar yang tepat guna dan tepat sasaran perlu dilakukan analisis kebutuhan siswa dan analisis bahasa (Sutami 2003). Dengan mengetahui kekhasan bahasa Mandarin, dapat dirancang kurikulum dan silabus yang sesuai dengan kebutuhan pemelajar Indonesia. Perancangan kurikulum dan silabus yang berkesinambungan hendaknya melibatkan Ditjen Pendidikan Menengah dan Dasar (Dikmendas) serta para ahli pengajaran bahasa Mandarin yang berpengalaman mengajar bahasa itu untuk orang Indonesia yang berbahasa ibu Bahasa Indonesia.

Pada tingkat perguruan tinggi Ditjen Pendidikan Tinggi (Dikti) memberikan aturan umum mengenai kurikulum progam studi Cina strata S1 dan D3. Muatan Mata kuliah Dasar Umum (MKDU) dan Mata Kuliah Dasar Fakultas (MKDF) ditentukan oleh Dikti. Muatan Mata Kuliah Keahlian (MKK) dan Mata Kuliah Pilihan (MKP) diserahkan kepada universitas penyelenggara program studi Cina strata S1dan D3. Melalui dua jenis mata kuliah ini dapat ditilik mutu sebuah program studi. Dikti dapat memeriksa kurikulum program studi S1 atau D3 sebuah universitas untuk mengetahui apakah sudah sesuai dengan statusnya sebagai S1 atau D3.

Selanjutnya, akan dibahas tiga hal yang dianggap mendesak untuk dilaksanakan, yakni kurikulum serta silabus, pengajar dan buku ajar.

\section{KuRIKULUM DAN SILABUS}

Ditjen Dikmendas sudah menyusun silabus bahasa Mandarin untuk SMA kelas $1-3$. Silabus ini tampak tidak didasari pada kebutuhan anak-anak Indonesia yang sama sekali tidak mengenal bunyi-bunyi bahasa Mandarin dan karakter Han, melainkan ditujukan kepada anak-anak yang berbahasa ibu bahasa Mandarin. Sebagai contoh, patut dipertanyakan kegunaan siswa pada semester 1 mengidentifikasikan bunyi inisial (shengmu) final (уипти). Bunyi inisial dan final merupakan pengetahuan teoretis tradisional yang hanya perlu dikuasai oleh pengajar ketika mengajarkan bunyi-bunyi bahasa kepada siswanya, lagipula analisis suku kata atas inisial dan final tidak ada di dalam bahasa Indonesia. Hal ini tentu menambah sebuah kesulitan bagi siswa. Selain harus menguasai bunyi yang tidak ada dalam bahasa Indonesia, mereka juga harus menguasai teori fonetik tradisional Cina.

Butir lain dalam silabus yang tidak didasarkan pada situasi nyata anak Indonesia adalah siswa mendiskusikan wacana lisan. Perlu diperhatikan bahwa yang diajarkan adalah kemahiran berbahasa, bukan kemampuan menelaah isi wacana. Dengan demikian, apakah perlu diskusi dilakukan pada tahap ini? Apakah mereka sudah mampu berdiskusi dengan kelancaran berbahasa, penguasaan jumlah kosa kata dan jenis kalimat terbatas? Apakah diskusi bukan salah satu mata pelajaran di tingkat lanjut?

Bahasa Mandarin sudah menjadi mata pelajaran wajib di sebagian besar sekolah DKI Jakarta. Penyusunan kurikulum dan silabus memerlukan pemikiran yang mendalam mengenai tujuan pengajaran, kebutuhan pasar, kebutuhan siswa yang disesuaikan dengan situasi di Indonesia. Penyusunan 
ini hendaknya melibatkan pakar pengajaran bahasa Mandarin atau pakar linguistik teoretis bahasa Mandarin yang sekurang-kurangnya berkualifikasi magister Sinologi.

\section{PENGAJAR}

Sejak tahun 2000 bermunculan penutur bahasa Mandarin yang secara "kilat" menjadi pengajar, karena tenaganya memang dibutuhkan di sekolahsekolah dan kursus. Padahal kualitas mereka dari sudut tingkat intelektualitas, pedagogi, teknik mengajar cukup diragukan. Keadaan ini dapat diperbaiki melalui pembenahan dengan rencana jangka pendek dan jangka panjang.

Pembenahan jangka panjang bertujuan menghasilkan pengajar lulusan universitas di Indonesia yang mahir berbahasa Indonesia dan bahasa Mandarin, mempunyai latar belakang sarjana Sinologi dan ilmu pendidikan. Hal ini dimaksudkan agar seorang pengajar mempunyai pengetahuan tentang sejarah, budaya, masyarakat RRT. Di samping mengajar bahasa, seorang pengajar juga dapat memperkenalkan sejarah dan budaya Cina, seperti siapa Kaisar Pu Yi, Qinshi Huangdi, apa itu Gugong, Yiheyuan, apa makna perayaan Imlek, Pecun. Pendidikan tenaga pengajar bahasa Mandarin dapat dilakukan di fakultas ilmu pendidikan dan keguruan-yang belum ada sampai saat ini.

Untuk rencana jangka pendek hal yang paling mendesak dilakukan adalah mengadakan pelatihan bagi para pengajar dalam metode pengajaran bahasa Mandarin. Departemen Pendidikan Nasional melalui Direktorat Pendidikan Luar Sekolah dan Pemuda (PLSP) telah membentuk subkonsorsium yang menangani pengajaran bahasa Mandarin pada jalur nonformal. Melalui kerja sama dengan beberapa universitas di RRT subkonsorsium ini telah beberapa kali mengadakan pelatihan metode pengajaran bahasa Mandarin dengan lokasi pelatihan di RRT atau di Indonesia. Usaha yang dirintis oleh subkonsorsium Dirjen PLSP ini sangat baik. Namun, arah dan tujuan yang hendak dicapainya belum dirumuskan dengan jelas. Sampai sejauh mana keberhasilan pelatihan yang sudah dijalankan, belum ada evaluasinya.

Dikmendas sebaiknya juga membentuk panitia khusus yang menangani pelatihan pengajar SMA dan SMK. Atau, Dirjen itu bekerja sama dengan subkonsorsium Dirjen PLSP. Panitia sekurang-kurangnya terdiri dari para pengajar bergelar magister dari program studi Cina bidang linguistik dengan spesialisasi linguistik teoretis atau pengajaran bahasa. Beberapa saran bagi panitia konsorsium dalam mengadakan pelatihan:

(1) pelatihan terdiri dari metode pengajaran, kemahiran bahasa Mandarin, kemahiran bahasa Indonesia;

(2) pelatihan dapat dilakukan oleh pakar pengajaran bahasa Mandarin dan Indonesia yang bekerja sama dengan universitas di RRT;

(3) dilakukan analisis kebutuhan pengajar dalam metode pengajaran, kemahiran bahasa Mandarin, kemahiran bahasa Indonesia;

(4) kekurangan yang ditemukan akan diisi melalui pelatihan. Pihak konsorsium memberitahukan pihak universitas RRT mengenai isi atau 
mata pelajaran yang akan diajarkan;

(5) pelatihan metode pengajaran dan kemahiran bahasa Mandarin dapat dilakukan dengan mengadakan kerja sama antara pakar Indonesia dan pakar RRT;

(6) pelatihan kemahiran berbahasa Indonesia dilakukan oleh pakar bahasa Indonesia;

(7) penentuan tingkatan peserta-dasar atau menengah-melalui tes penempatan;

(8) pengetesan untuk menentukan kelulusan.

Saran lain di samping pelatihan adalah mengadakan ujian kelayakan mengajar bahasa Mandarin. Hanya mereka yang lulus ujian itu dapat menjadi pengajar di SMA/SMK. Ujian kelayakan ini hendaknya bersifat nasional. Orang yang mengantungi ijazah tersebut dapat mengajar di sekolah mana saja di Indonesia.

\section{BUKU AJAR}

Pada tahun 2005 Tim MGMP dan Pengembang Kurikulum bahasa Mandarin SMA Provinsi DKI Jakarta menerbitkan buku Bahan Ajar Bahasa Mandarin untuk SMA kelas 1 dengan empat penyusun yang semuanya orang Indonesia. Dua di antaranya bergelar sarjana S1 dan magister studi Cina.

Topik yang disajikan cukup komunikatif, berbentuk dialog. Setelah itu terdapat daftar kata baru, latihan menulis karakter Han, latihan analisis kalimat atas subyek predikat obyek, latihan percakapan. Kelebihan buku ini adalah menyajikan topik yang diperlukan dalam komunikasi sehari-hari. Kekurangan buku ini adalah terlalu menekankan unsur tulis, dan gramatika. Unsur tulis muncul dalam bentuk dialog yang menggunakan karakter Han, latihan menulis karakter itu. Hal ini sangat menyulitkan siswa, karena siswa Indonesia "buta aksara Han". Arah komunikatif belum tampak, penekanan gramatika tampak nyata melalui analisis kalimat. Unsur lisan seperti bicara mendapat porsi sangat sedikit.

Buku lainnya Bahasa Tionghoa merupakan hasil kerja sama Departemen Pendidikan Nasional yang diwakili oleh Direktorat Jenderal Peningkatan Mutu Pendidik dan Tenaga Kependidikan, serta Direktorat Jenderal Manajemen Pendidikan Dasar dan Menengah dengan China National Office for Teaching Chinese as a Foreign Language (Hanban) dari RRT. Penyusun buku berasal dari RRT dan Indonesia.

Kelebihan buku ini, Hanyu pinyin selalu mengiringi karakter Han di dalam dialog, sehingga siswa dapat membaca dialog. Penyajian dialog secara situasional, format penyajian cukup menarik. Kekurangan buku ini, ilustrasi kurang menarik. Sama seperti buku pelajaran tradisional lainnya, buku ini masih menekankan kemampuan tulis seperti menerjemahkan, menyusun kalimat, menulis ke dalam karakter Han atau ke dalam Hanyu Pinyin. "Segi komunikatif yang dititikberatkan" seperti yang tertulis dalam Kata Pengantar belum tampak. 
Untuk mengatasi kekurangan di atas hendaknya Departemen Pendidikan Nasional melalui ditjennya melaksanakan proyek penyusunan buku ajar. Dalam penyusunan ini dilakukan analisis kebutuhan siswa Indonesia dan analisis bahasa. Berdasarkan hasil analisis disusun buku ajar dengan pendekatan komunikatif, sebuah buku yang dapat memenuhi kebutuhan siswa Indonesia pada saat ini di bidang fonetik, morfologi, sintaksis, semantik, dan pragmatik bahasa Mandarin.

\section{PENUTUP}

Pengajaran bahasa Mandarin baru berumur delapan tahun bila dihitung mulai dari masa Reformasi tahun 1998. Belum terlambat dan belum terlalu rumit untuk membenahi situasi pengajaran yang belum terarah dan belum sistematis ini. Tujuan pembenahan adalah membuat pemelajar mahir berbahasa Mandarin sesuai dengan jenjang pendidikan dan jenis pendidikannya. Pada jenjang sekolah menengah dengan jenis pendidikan umum (SMA) keterampilan yang diperoleh berbeda dengan yang jenis pendidikan kejuruan seperti pariwisata (SMKP). Begitu pula di jenjang perguruan tinggi. Keterampilan lulusan S1 berbeda dengan D3. Dengan memiliki pandangan dan tujuan serta sasaran yang jelas dari setiap jenjang dan jenis pendidikan ini diharapkan para dihasilkan dapat memenuhi kebutuhan bisnis.

Tujuan pengajaran dewasa ini tidak sama dengan puluhan tahun lalu ketika masih sekolah Cina masih berdiri di Indonesia. Yang harus disadari sekali adalah bahwa bahasa Mandarin merupakan bahasa asing yang kedudukannya sejajar dengan bahasa Inggris, Jerman, Jepang, dan bahasa asing lainnya.

Upaya pembenahan ini hendaknya dilakukan oleh Ditjen Pendidikan Sekolah Rendah dan Menengah dan Ditjen Pendidikan Tinggi Depdiknas yang bekerja sama dengan pakar linguistik teoretis atau terapan dari Program Studi Cina di Indonesia. Para pakar inilah yang akan membuat kurikulum, silabus, buku ajar, dan mengadakan pelatihan pengajar. Selain itu, juga dapat dilakukan kerja sama dengan pakar pengajaran Bahasa Mandarin dari universitas di RRT, Taiwan, Singapura, atau Malaysia dalam mencari metode pengajaran Bahasa Mandarin yang efektif khusus bagi penutur Bahasa Indonesia.

Dengan sistem pengajaran yang terarah dan jelas diharapkan para lulusan dari pelbagai jenjang dapat berkiprah di dunia bisnis tingkat internasional maupun nasional dalam era globalisasi ini.

\section{DAFTAR ACUAN}

Alwi dan Dendy Sugono. 2003. Politik Bahasa: Rumusan Seminar Politik Bahasa. Jakarta: Pusat Bahasa.

Govaars-Tjia, Ming Tien. 2005. Dutch Colonial Education: the Chinese Experience in Indonesia, 1900 1942. Diterjemahkan oleh Lorre Lynn Trytten. Singapore: Chinese Heritage Centre.

Halim, Amran. 1980a. "Fungsi politik bahasa nasional" dalam Politik Bahasa Nasional 1, hlm. 13-25. Jakarta: Balai Pustaka. . 1980b. "Fungsi politik bahasa nasional" dalam Politik Bahasa Nasional 2, hlm. 
19-28. Jakarta: Balai Pustaka.

Kartono, Giri. 1980. "Kedudukan dan fungsi bahasa asing di Indonesia" dalam Politik Bahasa Nasional 2, hlm. 121 -130. Jakarta: Balai Pustaka.

Retmono. 1980. "Pengajaran bahasa asing dalam rangka politik bahasa nasional" dalam Politik Bahasa Nasional 2, hlm. 131-142. Jakarta: Balai Pustaka.

Suryadinata, Leo. 1984. Dilema Minoritas Tionghoa. Jakarta: PT Grafiti Pers.

Sutami, Hermina. 2003. "Peningkatan Mutu Pengajaran Bahasa Asing NonInggris: Khususnya Bahasa Mandarin" dalam Kongres Bahasa Indonesia VIII, 14-17 Oktober 2003 di Jakarta.

Tjahjadi, Lilysagita. 2006. "Pengajaran Bahasa Cina di Indonesia" makalah Seminar Internasional Pengajaran Bahasa dan Dinamika Budaya Asia di Asia. Diselenggarkan di Jakarta oleh FIB UI dan Hankuk University of Foreign Studies, 12 Januari 2006. 